\title{
Editorial: Marketing Automation - Myth or Magic?
}

'Automation is the future of marketing' said a banner at a recent CRM conference. This stopped me dead in my tracks. Will automata replace all marketers in 2001?

Somehow I very much doubt that automation will change marketing in my lifetime. Most marketing professionals see their role as essentially creative. It is patently absurd to suggest that robots will soon be challenging our most creative people.

HAL, the electronic brain in 2001 is pure science fiction. No creative department will hire robots on to its staff. We will not have automata running marketing departments by next year, nor in the next decade. So what is all the fuss about 'marketing automation'.

Software is likely to have a beneficial effect on marketing professionals in two areas - pattern recognition and managing complexity. On the other hand this 'automation' software will not actually automate any jobs. This is a serious point and not just about semantics.

Automation is what caused Microsoft Word to suggest that the previous sentence should read, 'These is a serious point and not just about semantics'. Automation of office work has not delivered significant business benefits. Certainly we can e-mail more colleagues than ever before. However, the business benefits of automating management are questionable, and information economists such as Paul Strassman and Kit Grindley have raised a question mark over the benefits of such automation.

Marketing automation technology in the right hands has the capacity to create substantial benefits. Intelligent users of such technology can control the complexity of thousands of customer relationships and deliver the right offer to the right customer at the right time. They can also identify opportunities and threats in the marketplace faster and with more accuracy than their computer illiterate colleagues.

Marketing automation technology in the wrong hands, however, can be disastrous. Automation of postal mailshots has become a nuisance for many consumers. Automating junk email will make matters worse. Automating replies to email will continue to erode customer satisfaction, just as automating help lines has done in the recent past. 'Marketing automation' technology on its own will not create value for customers or shareholders.

4 Journal of Targeting, Measurement and Analysis for Marketing Vol. 9, I, 4-6 (c) Henry Stewart Publications 0967-3237 (2000) 
The central problem is marketing's failure to integrate itself with the firm's basic objective of maximising shareholder value. Marketing suffers both as a profession and an academic subject from having hazy objectives. Many marketing staff believe that the objective of marketing is to increase sales. But for an intelligent board of directors, such an objective is absurd. Any first-year economics student can demonstrate that maximising sales is an extremely unprofitable strategy. Yet marketing automation used unintelligently can create sales and destroy profits.

Another favoured goal of marketers is to develop strategies aimed at maximising customer satisfaction. But again this makes little sense. Offering lower prices, special deals, and promotional gifts may temporarily reduce dissatisfaction with poor products and services, but the end result of such strategies is unhappy shareholders, who find the company is giving away its profits to bribe unhappy customers.

An alternative tack pursued by some marketing managers intent on winning the confidence of the finance director is to develop strategies that maximise current profitability. But this is a hopeless trap for marketing. Customers who temporarily become unprofitable are 'fired', irrespective of circumstances. Products that are temporarily unprofitable are 'pruned', even the new products which have not yet reached maturity or profitability. Because of the lagged effect of most marketing investment, cutting rather than increasing these investments will always boost short-term profitability. A focus on maximising short-term profits is no help when creating sustainable shareholder value.

The starting point in deciding how 'marketing automation' technology ought to be used is to properly define its objective. Today, virtually all major companies accept that the primary task of management is to maximise shareholder value. The objective of marketing needs to be redefined to align itself with this fundamental business goal. At Cranfield Business School we call this approach Marketing Value Added (MVA), and have created a research club to investigate best practices.

Accepting the new concept of marketing as a driver of shareholder value in no way weakens the traditional contribution of marketing. Rather it enormously strengthens it. Marketing is the most important driver of sustainable profitable growth. This is achieved as follows. First, customer insight delivers a steady flow of new opportunities, enabling worn-out products and services to be replaced with new ones that customers want to buy. Secondly, customer profitability analysis enables firms to build profitable relationships, leaving the unprofitable ones for competitors. Thirdly, customer defection root-cause analysis provides tools for combating revenue volatility and risk. Finally, marketing uses customer value positioning to obtain enduring premium prices, especially by using branding. 
Marketing Value Added uses relatively straightforward financial analyses - often using no more than PC-based spreadsheets, to demonstrate how the strategies that they are proposing enhance long-term earnings growth and produce specific measurable increases in shareholder value. It enables marketing strategies to be rooted in the boardroom.

Marketing automation provides the operational tools for executing MVA strategy. Segmentation, targeting and positioning are central concepts to an MVA approach, and they need powerful tools to make them operational. This is where the 'marketing automation' software fits in - it is the key tool for delivering customer value, but it depends on there already being an MVA strategy in place.

Buying marketing automation software is a good move, so long as the strategy is in place. Our research shows that creating an MVA strategy is not difficult. Senior management can develop it in a few days using structured workshops to define objectives and strategies, and linking marketing targets to shareholder goals.

If marketing needs to create shareholder value to be credible, shareholders also need to recognise the value added by marketing. Finance cannot create value-adding strategies without marketing. All too often this role has been filled by financial management who have focused on cost reduction and automation as a way to increase value. But what is clear today is that growth is the most effective way of creating value for shareholders. All the companies that have created the greatest shareholder value in the last decade - Microsoft, Dell, Charles Schwab, Intel, Gap - have been high growth companies with strong brands. Marketing has an essential role in creating such value-adding strategies.

ROBERT SHAW

Managing Editor August, 2000

6 Journal of Targeting, Measurement and Analysis for Marketing Vol. 9, I, 4-6 (c) Henry Stewart Publications 0967-3237 (2000) 